\title{
RESENHA CRÍTICA: STREECK, Wolfgang. How Will Capitalism End: essays on a failing system. Londres: Verso, 2016.
}

\author{
CRITICAL REVIEW: STREECK, Wolfgang. How Will Capitalism End: essays on a failing \\ system. Londres: Verso, 2016.
}

Pedro Txai Leal Brancher ${ }^{1}$

\section{RESUMO}

A mais recente obra de Wolfgang Streeck, diretor emérito do Instituto Max Planck, oferece uma perspectiva original sobre a globalização financeira contemporânea. De acordo com o autor, as instituições políticas que mitigavam o efeito das contradições do capitalismo se desintegraram. Desse modo, estaríamos diante de um período de caos sistêmico, no qual crises e conflitos serão cada vez mais recorrentes.

Palavras-chave: Capitalismo; Globalização; Crise.

\begin{abstract}
The latest book of Wolfgang Streeck, director emeritus of the Max Planck Institute, offers a unique perspective on contemporary financial globalization. According to the author, the political institutions that used to mitigate the effects of the contradictions of capitalism were disintegrated. Thus, we would now be facing a period of systemic chaos in which crises and conflicts are increasingly recurrent.
\end{abstract}

Key Words: Capitalism; Globalization; Crisis.

Previsões sobre o fim do capitalismo geralmente incluem a perspectiva da emergência de um modo de produção superior. No entanto, para Wolfgang Streeck, diretor emérito do Instituto Max Planck, a existência de uma ordem substituta não é condição necessária para a desintegração do sistema capitalista. Pelo contrário, para ele, a ausência de um projeto opositor catalisa o potencial destrutivo das contradições inerentes à acumulação de capital. Nesse contexto, ao longo dos ensaios que constituem o livro "How Will Capitalism End?", o autor expõe a tese de que a globalização financeira do capital desintegrou as instituições que mitigavam essas contradições e, assim, impediam a autodestruição do capitalismo.

\footnotetext{
${ }^{1}$ Doutorando em Ciência Política pelo Instituto de Estudos Sociais e Políticos (IESP) da Universidade Estadual do Rio de Janeiro (UERJ). Mestre em Estudos Estratégicos Internacionais pela Universidade Federal do Rio Grande do SUL (UFRGS).
} 
Wolfgang Streeck, professor de Sociologia na Universidade de Colônia, no norte da Alemanha, dedica-se ao estudo das relações entre Estados, democracia e capitalismo há mais de 40 anos. Sua agenda de pesquisa situa-se na intersecção entre as abordagens neomarxista e neoweberiana; portanto, compreende processos de mudança social como resultantes das interações entre modelos de acumulação de capital e configurações institucionais distintas. Contemporaneamente, em suas duas obras mais recentes, “Buying Time: The Delayed Crisis of Democratic Capitalism" (2014) e "How Capitalism Will End" (2016), o interesse fundamental de Streeck foi o de avaliar os impactos políticos, sociais e econômicos da ascensão do neoliberalismo enquanto o modelo social internacionalmente dominante.

Nessa perspectiva, os três primeiros capítulos de "How Capitalism Will End" são constituídos por ensaios que delineiam o modelo conceitual utilizado pelo autor. Nesse momento, evidencia-se a perspectiva de Streeck sobre as características do período imediatamente posterior à desintegração do capitalismo, os efeitos da financeirização sobre a qualidade das instituições democráticas e os impactos sociológicos do consumismo como fundamento para a cidadania. Os quatro capítulos posteriores analisam empiricamente a crise econômica e política da União Europeia. 0 objetivo do autor é o de demonstrar as causas e consequências da apropriação das instituições supranacionais europeias por parte de uma pequena aristocracia constituída por instituições financeiras privadas. Por fim, Streeck discute a maneira pela qual as Ciências Sociais analisam o capitalismo contemporâneo e fornece indicações para a continuação dessa agenda de pesquisa.

Entretanto, considera-se que, apesar de a obra elucidar as características dos conflitos distributivos que derivam da globalização financeira contemporânea, argumenta-se que dois elementos enfraquecem a previsão do autor sobre o declínio inexorável do capital. Em primeiro lugar, os sintomas descritos no livro parecem indicar mais a crise da democracia representativa liberal do que a desintegração do modo de produção capitalista. Em segundo lugar, o diagnóstico sobre a incapacidade de os Estados enfrentarem os interesses predatórios do setor financeiro desconsidera as experiências recentes de desenvolvimento no leste e sudeste asiático.

Primeiramente, nota-se que parte do argumento central de Wolfgang Streeck não é nova: serão as contradições endógenas do sistema que transformarão a crise atual 
do capitalismo em sua última. No entanto, segundo ele, a diferença, dessa vez, é que não se trata de um declínio cíclico na dinâmica de acumulação, mas sim de um longo processo de decaimento decorrente de múltiplas crises simultâneas. Logo, a originalidade da tese de Streeck é a de conceber o fim do sistema capitalista como o resultado de uma morte gradual por milhares de pequenos cortes.

O segundo elemento central da obra é a perspectiva pessimista sobre o período imediatamente posterior ao capitalismo. Segundo o autor alemão, em função da inexistência de projetos opositores, o momento pós-capitalista será caracterizado por desordens sistêmicas recorrentes. As antigas instituições responsáveis pela regulação da vida social estarão incapacitadas e não haverá novas para substituí-las. Em outras palavras, Streeck avista uma época de interregno, marcada pela dissolução da integração coletiva, instabilidade e insuficiência de governança no nível macrossocial:

\footnotetext{
Antes do capitalismo acabar, ele permanecerá em um limbo, morto ou quase morrendo em função de uma overdose de si mesmo, mas ainda bastante presente, na medida que ninguém terá o poder para retirar seu corpo decadente do caminho (STREECK, 2016, p.36, tradução nossa).
}

A previsão do autor parte do pressuposto de que o capitalismo é um sistema intrinsicamente instável e constantemente desequilibrado. Por conta disso, sua continuidade histórica só é possível em razão da existência de forças políticas contrárias à tendência desenfreada de acumulação de capital. Ou seja, o capitalismo necessita ser resguardado dele mesmo para sobreviver. No entanto, a hipótese levantada pelo autor é que, atualmente, esses contrapesos se desintegraram, e não haveria nada mais capaz de impedir a autodestruição do sistema. Consequentemente, em breve, o capitalismo será vítima de sua própria hegemonia.

O núcleo teórico dessa ideia fundamenta-se na concepção desenvolvida por Karl Polanyi (2000) sobre a relação entre mercado e sociedade, em sua obra clássica " $A$ Grande Transformação". De acordo com Polanyi, a acumulação de capital só avança de maneira sustentável na medida em que a terra, o trabalho e o dinheiro forem resguardados da dinâmica do mercado. Isso ocorre porque: (1) a produção e o consumo desenfreados eliminam a sustentabilidade de uso dos recursos naturais no longo prazo; 2) a exploração descomedida da força de trabalho extingue as possibilidades de 
integração social e reduz a indução do crescimento econômico por meio da demanda agregada; e (3) a financeirização descola a geração de riqueza do processo produtivo, transformando a lógica D - M - D`, identificada por Karl Marx, em D-D', ou seja, o lucro empresarial se torna independente da geração de valores de uso. Logo, a total incorporação desses três elementos à forma mercadoria os destrói, inviabilizando a continuidade do processo de acumulação.

Por conta disso, parte do esforço empírico da obra é demonstrar a trajetória histórica que resultou no enfraquecimento das instituições coletivas responsáveis por frear a commodificação desses três elementos. Segundo o autor, esse processo originouse com as respostas dadas à crise da economia keynesiana nos países da OCDE ao final da década de 1970. Neste momento, teria emergido um modelo econômico 'neoliberal Hayekiano', no qual as expectativas de crescimento passam a derivar da redistribuição oligárquica (de baixo para cima) e da exploração desenfreada da força de trabalho.

Streeck identifica três conjunturas críticas no processo de formação do 'capitalismo neoliberal Hayekiano'. Em primeiro lugar, a escalada inflacionária no final da década de 1960 que resultou no aumento das taxas de juros pelo Federal Reserve Bank e gerou aumento substancial do desemprego. Em seguida, ao longo dos anos 80, os problemas inerentes às altas taxas de desemprego foram respondidos por meio do crescente endividamento público (debt state). No entanto, esse endividamento ocorreu menos em função do incremento dos gastos em seguridade social e mais pelas políticas de juros altos e ao declínio da capacidade extrativa dos Estados frente ao avanço da mobilidade do capital fictício. Desse modo, ao mesmo tempo que cresceu a participação do setor financeiro na economia, criou-se um "hiato entre os meios fiscais que os governos podiam mobilizar sobre as relações de produção e propriedade e as demandas por apoio estatal requeridas por avançadas economias capitalistas" (STREECK, 2016, p.115, tradução nossa).

O período subsequente - décadas de 1990 e 2000 - distingue-se pela 'restauração' das finanças públicas por meio da privatização e/ou eliminação das instituições responsáveis pelas políticas de bem-estar, isto é, pela formação dos EstadosConsolidados (consolidated states). Esse declínio no provimento dos serviços estatais foi, em parte, compensado pela oferta desenfreada de crédito barato. No entanto, essas condições estimularam a especulação com ativos de alto risco, criaram bolhas e crises 
financeiras, originaram um massivo endividamento privado e, consequentemente, resultaram na crise de 2008.

Portanto, nota-se que, apesar de essas respostas terem prolongado a sobrevida do sistema, de fato, elas apenas potencializaram seu declínio no longo prazo. Ademais, o baixo crescimento econômico (estagnação), a desigualdade econômica (redistribuição oligárquica) e o endividamento tornaram-se sintomas simultâneos, mutuamente constituídos e irreversíveis. Por um lado, a desigualdade reforça a tendência de baixo crescimento que, por sua vez, assevera o conflito redistributivo, reforçando a redistribuição oligárquica. Por outro, o endividamento público e privado robustecem a financeirização, enfraquecendo ainda mais a retomada do crescimento e reforçando a desigualdade. Ou seja, magistralmente, o autor descreve a armadilha em que se encontra a economia global: o modelo de acumulação de capital teria se tornado incapaz de engendrar um padrão sustentável de crescimento $^{2}$.

Além da estagnação e da redistribuição oligárquica, Streeck identifica o avanço do setor privado sobre o domínio público (privatização), a corrupção e a anarquia global como outros três sintomas essenciais da desordem sistêmica contemporânea. A tomada do domínio público ocorreria na medida em que a privatização de ativos estatais se torna uma das únicas possibilidades de retomada do lucro empresarial em uma economia estagnada. A consequência é que a universalidade dos serviços públicos básicos é substituída pela exclusividade caraterística do setor privado. Assim, o Estado é desprovido dos meios capazes de mitigar os efeitos sociais nocivos do capitalismo. A instabilidade social resultante pode ser identificada pelo incremento da população em situação de desemprego estrutural e pela crescente pobreza nos países da OCDE.

Por sua vez, o autor conceitua a corrupção como a quebra da relação entre a racionalidade moral protestante e a acumulação capitalista. Ou seja, a lucratividade do setor financeiro exige a constante quebra de regras em busca de lucros extraordinários, bem como o resgate público no momento em que essas práticas geram crises especulativas. Logo, o sintoma nomeado como 'corrupção' por Streeck parece, de fato,

\footnotetext{
${ }^{2}$ Nota-se também a incapacidade das autoridades de realizarem políticas que revertam o problema, já que as taxas de investimento não respondem mais às políticas fiscais e monetárias expansionistas keynesianas. Por exemplo, a recente injeção de dinheiro fácil por meio de política monetária expansionista do Banco Central Europeu - 'quantitative easing' - teria, mais uma vez, apenas adiado o problema e incentivado o endividamento dos agentes. Em outras palavras, ninguém parece saber o que fazer.
} 
referir-se à captura dos mecanismos democráticos de decisão por uma tecnocracia financeira movida pela acumulação de curto prazo $^{3}$.

Esse diagnóstico não implica, no entanto, uma percepção generalizada do caráter corrupto do setor financeiro na população. Até porque, enquanto a mídia demoniza os atores políticos continuamente, há poucas menções às práticas criminosas exercidas por instituições financeiras. Ao contrário, a hegemonia exercida por esse setor na definição da agenda de debate público faz que seu conceito no imaginário popular esteja relacionado com valores como ousadia e coragem, e não com transgressão e ganância. Desse modo, o que Streeck caracteriza como um sintoma de degradação sistêmica pode ser interpretado como uma crise das instituições democráticas representativas nessa nova fase de acumulação do capital.

A última desordem sistêmica apresentada - a anarquia global - é identificada como sendo as consequências do declínio do poder econômico e militar dos Estados Unidos para a ordem internacional, principalmente em relação à manutenção do dólar enquanto moeda forte. Contudo, ao dedicar poucas páginas à análise desse assunto controverso na literatura, o autor produz um argumento assertivo sem oferecer a sustentação teórica e empírica necessária. Por exemplo, nota-se a inexistência de consenso sobre a instabilidade de um mundo multipolar. Ao contrário, a longa duração de sistemas interestatais nos quais duas ou mais potências coexistiram sugere a fraca correlação entre unipolaridade e estabilidade 4 .

Além disso, mesmo se admitíssemos o papel estabilizador exercido pelos EUA no período imediatamente posterior à Segunda Guerra Mundial, é necessário reconhecer que, pelo menos desde meados dos anos 60, a política externa estadunidense atuou à margem das instituições internacionais quando elas contrariaram seus interesses. 0

\footnotetext{
${ }^{3}$ Essa afirmação se evidencia na medida em que cada vez mais as decisões referentes às taxas de juros, a oferta monetária e a regulamentação financeira são relegadas a bancos centrais e agências reguladoras insuladas de pressões eleitorais, mas extremamente permeáveis ao lobby de grupos econômicos. 0 caso do Banco Central europeu é exemplar, pois ele se constitui como uma organização supranacional capaz de impor políticas de austeridade aos países membros do bloco à revelia de suas populações.

${ }^{4}$ Exemplos de abordagens nesse sentido são as obras de Kenneth Waltz (1979), "Theory of International Politics" e de Victória Tin Bor-Hui, War and state formation in ancient China and early modern Europe. No primeiro caso, Waltz demonstra o efeito estabilizador que a competição entre duas superpotências dotadas de capacidades nucleares de segundo ataque (bipolaridade) gerava sobre o nível de conflito no sistema internacional durante a Guerra Fria. Victória Tin Bor-Hui, por sua vez, demonstra a longa duração do sistema multipolar de reinos soberanos na antiguidade chinesa antes da unificação realizada pela dinastia Qin. Assim, percebe-se que o possível declínio dos Estados Unidos na ordem global contemporânea não significa, necessariamente, o aumento da instabilidade entre as nações.
} 
abandono dos acordos de Bretton Woods para assegurar a liberdade de financiamento do déficit decorrente dos gastos na Guerra do Vietnã, a recusa em assinar tratados internacionais e as invasões do Iraque e do Afeganistão sem a anuência do Conselho de Segurança das Nações Unidas são alguns exemplos do comportamento desestabilizador exercido pelo governo estadunidense nas últimas décadas. Portanto, pode-se argumentar que o declínio dos EUA representou o enfraquecimento do Estado que mais contribuiu para a instabilidade da ordem internacional contemporânea.

Assim, nota-se que o argumento melhor sustentado ao longo da obra é o de que a consequência do surgimento de um modelo de acumulação dominado pelas finanças foi colocar por terra a relação entre capitalismo e democracia. Isso é válido porque o Estado-Consolidado é aquele cujo compromisso político fundamental é com mercado financeiro internacional, e não com os objetivos politicamente definidos por seus cidadãos. Especificamente, a remuneração de investidores, o controle do déficit público e a austeridade fiscal são finalidades mais importantes do que a manutenção do emprego e o provimento de bem-estar. 0 resultado é o crescimento do antagonismo entre o que Streeck denomina de 'povo do Estado Nação' e de 'povo do mercado internacional'.

Por meio da distinção entre 'povo do Estado-nação' e 'povo do mercado internacional', o autor alemão estabelece uma tipologia do conflito fundamental no capitalismo globalizado e financeirizado. Dadas as dificuldades enfrentadas por sindicatos e movimentos trabalhistas, bem como o amplo acesso aos recursos financeiros por instituições financeiras internacionais, a correlação de forças nessa disputa é extremamente desequilibrada. Assim, a capacidade de pressão política do setor financeiro é enorme, seja pelo financiamento de campanhas eleitorais, ataques especulativos ou ameaças de fuga de capitais ${ }^{5}$.

Essa desproporcionalidade na correlação de forças políticas é evidenciada pelo avanço contundente de legislações que, por um lado, afrouxam os constrangimentos à mobilidade e à especulação de ativos financeiros e, por outro, limitam a capacidade de gestão macroeconômica por parte dos Estados. 0 resgate aos bancos promovido pelo

\footnotetext{
${ }^{5}$ Soma-se a isso o fato de que os interesses do "povo do mercado internacional" também são defendidos por um conjunto de organizações internacionais, como o FMI, o Banco Mundial e as Agências de Rating, que atuam como disciplinadoras do comportamento dos governos e gerenciadoras das expectativas dos mercados.
} 
governo Obama nos EUA após a crise de 2008 e a aprovação da PEC 55 pelo Congresso brasileiro em 2016, são exemplos das diretrizes de um Estado Consolidado. Enquanto o primeiro tornou públicos os prejuízos causados pela especulação desenfreada em busca de lucros de curto prazo por Wall Street, o segundo comprometeu-se constitucionalmente a priorizar os interesses do capital financeiro em detrimento da provisão de investimentos públicos e bem-estar para seus cidadãos. Ou seja, avança a criação de uma proteção institucional à especulação financeira.

No entanto, ainda que a hipótese levantada pelo autor sobre a captura das instituições estatais pelo mercado financeiro se sustente, 0 argumento sobre 0 enfraquecimento global do Estado-nação em relação ao capital financeiro precisaria ser melhor elaborado. Isto porque, embora seja evidente a submissão de determinados países às pressões financeiras, identificam-se outros - principalmente no leste e sudeste asiático - que mantiveram capacidade suficiente para disciplinarem os mercados e perseguirem projetos nacionais politicamente definidos. Logo, salienta-se que a tese de Streeck é enfraquecida pela ausência de análises teóricas e empíricas sobre as características econômicas e sociais de países fora do eixo EUA e UE.

Nesse sentido, destacam-se as pouquíssimas linhas utilizadas por Streeck para descartar a possibilidade de a República Popular da China representar tanto um modelo alternativo de desenvolvimento capitalista quanto uma fiadora de uma nova ordem interestatal ${ }^{6}$. Atualmente, a China possui o segundo maior PIB do mundo e sua população é três vezes maior do que a da União Europeia. Além disso, o país não somente não sofre de estagnação - suas taxas de crescimento se mantiveram acima dos 6\% na última década -, como também o governo controla os efeitos da financeirização ao conservar fortes restrições ao setor bancário e à mobilidade de capitais. Desse modo, não se trata de afirmar que a acumulação de capital promovida por Beijing não seja permeada por graves contradições, mas sim de que elas não são as mesmas enfatizadas por Streeck como os sintomas de uma crise global do capitalismo.

Em suma, considera-se que "How Will Capitalism End?" é bem-sucedido na crítica ao pressuposto da autorregulação do mercado proclamado pelos teóricos

\footnotetext{
${ }^{6} \mathrm{~A}$ pouca atenção dedicada pelo autor às experiências asiáticas impressiona ainda mais quando são comparados os indicadores demográficos e econômicos da região em relação à União Europeia (UE). A China possui, sozinha, o segundo maior PIB do mundo e uma população de quase três vezes a de todos os países da UE somados.
} 
neoclássicos. Desse modo, a obra é basilar para o desenvolvimento de um programa de pesquisa que trate o capitalismo como um sistema aberto e historicamente delimitado, no qual crises e desequilíbrios sejam a norma e não, a exceção. Ademais, a análise empírica densa sobre os efeitos econômicos e políticos produzidos pelo avanço da globalização financeira nos países da OCDE torna a obra essencial para a compreensão dos conflitos sociais que emergem no capitalismo contemporâneo.

Todavia, considera-se que o argumento de que a crise da democracia liberal representativa seja uma ameaça real ao capitalismo requeira maior elaboração. Isto porque o que Streeck prevê parece não ser tanto o fim do sistema capitalista, mas, sim, o declínio das forças que permitem sua coexistência com instituições políticas democráticas ${ }^{7}$. Por fim, salienta-se que a contraposição do modelo analítico à luz de uma das experiências recentes de desenvolvimento econômico no leste e sudeste asiático principalmente na China - é fundamental para que a tese de que os Estados-nacionais contemporâneos sejam incapazes de se contraporem aos interesses do 'povo do mercado internacional' seja mais robusta.

\section{Bibliografia}

HUI, Victoria Tin-bor. War and state formation in ancient China and early modern Europe. Cambridge: Cambridge University Press, 2005.

STREECK, Wolfgang. Buying Time: The Delayed Crisis of Democratic Capitalism. a London: Verso, 2014.

STREECK, Wolfgang. How Will Capitalism End: essays on a failing system. London: Verso, 2016.

WALTZ, Kenneth. Theory of International Politics. Reading, Mass: Addison-Wesley Publishing Company, 1979.

\footnotetext{
${ }^{7} \mathrm{Ou}$ seja, a propriedade privada dos meios de produção deve continuar existindo, ainda que seja resguardada por sistemas políticos cada vez mais autoritários e exponencialmente desiguais.
} 